\title{
The Dilemma and Outlet for the Development of College Students Sport
}

\author{
Association \\ Xin $\mathrm{Li}^{1, \text { a }}$, Jingjing Guan ${ }^{1, b}$ \\ ${ }^{1}$ Qiqihar Medical University, Qiqihar City, Heilongjiang Province, 161006, China \\ aemail:360121833@qq.com bemail:33094995@qq.com
}

Key words: College students; Sports association; Development; Dilemma; Outlet

\begin{abstract}
With the national emphasis on university sports, sports associations of university student are increasing. The university sports has played an increasingly important role in the enriching campus culture, promoting the healthy development of university students, creating a harmonious campus and cultivating students' lifelong sports consciousness. However, a series of problems of university sports associations itself have become increasingly prominent, which hinders the development of sports associations of university students in a certain extent. Based on the learning and practical experience of the author, this paper first analyzed the reality of the dilemma of the development of university sports associations, and then put forward relevant countermeasures.
\end{abstract}

\section{Introduction}

With the rapid development of our society and higher education reform, the development on sports associations of university students has shown a trend and situation about extracurricular activities being increased, community activities and social situation being more closely linked. At the same time, the university sports associations in the development exists many problems about imperfect management system and unbalanced development between different associations. In the situation of the rapid development of society, the following problems about how to strengthen and improve sports associations of university students, and how to realize the innovation of management synergy mechanism and linkage development, and how to further clear the development of university sports associations are worth thinking and making research.

\section{Real Dilemma of the Development of University Sports Associations}

Sports association internal management mechanism is not perfect and lacks innovation and development mechanism. First of all, the university sports associations lack class distinction. Most of the universities have not set up the evaluation standards of all associations, so associations are treated equally, which affects the enthusiasm of the development of association. Some university sports associations are not make timely clear cut on sports associations, and they are lack of effective means of supervision on the daily activities of sports associations. This leads to some sports associations welcomed by university students are not accept sufficient supports from the school level, which affects its deeper development. Secondly, the development of university sports associations are lack of market guidance and support related to commercial operation. Most of considerations from the university managers are funding and effects of the relevant sports. Whether 
the sports associations equip with market and business operation abilities or not, it is not the focus. Moreover, the organizer and members are not understand well about the market and business operation ways, so the commercial development of university sports associations is low.

The development of sports associations are lack of coordination. As a sports association, which purpose is to cultivate the students' ability and adapt to the society through this platform; further, it can promote university students to quickly integrate into the society. At present, many universities sports association activities are carried out on the basis of internal "self-pleasure." Cases about getting out of university and making coordination with other sports association are very limited. The development of university sports associations are always at a low level in the stagnant, which is the result of limited communication scope and lacking communication roads. The fundamental reasons are including limited special funds and lacking association management at all levels of macro guidance and planning of the work between the different university sports associations. The university sports associations carry out activities only by themselves, which lead to the situation about the university sports associations cannot form a linkage mechanism of complementary advantages, hindering the healthy development of the university sports associations.

The degree of attention from university sports association management needs to be improved. The attention from university sports association management is the guarantee to the student sports associations. Some association activities cannot do without coordination and support from several university departments. Without the helps from relevant management departments in the capital, site, personnel aspects and so on, sports associations are difficult to do special activities, and cannot achieve remarkable results. Attention from university management department is a strong guarantee for the development of students' sports associations. Such supports from university management department will solve the existing problems in sports associations better. The development of sports association is lack of features, and the promotion is insufficient with many low level activities, thus a lot of sports associations cannot gain strong support from the university management department. This has gradually formed the situation of lacking importance on sports association, thus affecting the further development of the university sports association.

\section{The Development Strategies on Sports Associations of University Students}

Improve association internal management mechanism, and strengthen the development power of sports associations. Improving the internal management mechanism is the only way for the development of sports associations. The problems about how to make the new members continue to increase and make the old members no longer loss, are the primary issues of sports associations in the internal management. It is also the premise of the cohesion of the association culture. In this regard, it is necessary to solve the following problems. First, we should improve the sports association recruitment threshold and its recruitment mechanism. Talent is the first priority and is the guarantee of all the work. More new members and recruitment are not our goal, and the key point is to form a joint force, so that to work towards a common goal. The recruitment job is not simply to consider new members' skills, which emphasize on their work enthusiasm. Second, we should make a comprehensive market-oriented operation, so that to create an open sports association. Throughout the history of the development of sports associations of university students, it is not difficult to find that the sports association are limited within university and students can not regard the sports association activities as their careers. Only let the sports associations create wealth in the market, can sports associations bring benefits to university and students. Third, talking about culture is not as good as strengthening the practice of sports associations. The flag, emblem and shouting out slogans are just superficial things, which cannot fundamentally solve the problem. 
Thus, culture needs carrier, and the best carrier is sports. Therefore, organizing every sports activity is the foundation of developing association culture.

Broaden exchanges of sports associations, and foster a good association culture. Foreign exchange is an important way to cultivate the association culture, so we should broaden exchanges and strengthen communication between the different associations. We should vigorously encourage the association to go out of the university gate, and enter the society to communicate with other colleges and universities, or cooperate with sport associations, so that to jointly carry out sports activities. At the same time, we should play the role of the members of the association. Unity is an important guarantee for the stable development of sport association. "Both together do best of all", so we should use the wisdom of the group to gather manpower, material resources, financial resources in one place, so that to mobilize the enthusiasm of each members and participate in the activities. We should actively gather the personal behavior and the honor of a association, which can burst out greater creativity through continuous communication. In addition, we should cultivate good association culture. The outstanding sports association culture is the spirit that formed in the long-term practice of operating. It is the core of association. Therefore, association leaders should try to create a good atmosphere, and truly let members say something directly as masters in sport association. Moreover, they should give full play to the initiative, and actively let members participate in the activities of the association.

Establish a full range of organization and operation mode to ensure the continuity of association management work. From the establishment of university sports associations to the development, which will experience different stages, and limited by various factors. Each stage of the association management, culture, mechanism, operation and other aspects will present different characteristics. A full range of organization and operation mode can ensure the continuity of association management work. Reasonable operation mode is the necessary condition for the realization of sports association from weak to strong, and also to ensure the continuity of the management of sports association. This is the premise to link the focus of the sports association management work with continuous and comprehensive attention. Therefore, measures should be taken from the following two aspects. First, they should implement university management measures and strengthen responsibility of association. The management of the sports associations should be done for some purposes within their own jurisdiction; they should guide from the macro direction, and supervise on the details. Second, they should establish sports association elimination mechanism and publicize association affairs. In addition, they should eliminate empty sport association and make room for development of other associations.

Increase the management and investment of sports associations from the school level, and organize activities to promote its development. The fundamental meaning of the existence of an association is to successfully hold various activities to meet the needs of different students. Without activity, it will lose the meaning of establishing an association. The basic characteristics of sports association are emphasizing skills and activities. It is an effective way to guarantee the development of association by conducting reasonable guidance on various activities. First, we must strengthen the allocation of university physical education resources management. We should utilize time allocation of sports venues reasonably, so that to improve the utilization rate of sports venues. At the same time, we should mobilize the enthusiasm of various departments and faculties with professional advantage and resource advantage, so that to make them participate in the construction of student associations. Secondly, we should unify the allocation and self-employment to ensure that each student sports association teachers play a real role. Thirdly, we should guide the sports association to implement the financial budget system, so that they can survive by themselves. The 
funds for the activities of the association should be unified managed by the federation of university associations. Each activity has to write detailed plans and makes application for funding.

\section{Summary}

As an important part of university sports culture, sports associations of university student play the increasingly important role in enriching campus culture, promoting the healthy development of college students' physical and mental health, and creating a harmonious campus. At present, the development of the sports associations also exist some problems, including the mode of operation being not coordinated, insufficient attentions on sports association from university and imperfect internal management mechanism and insufficient development power of sports association. In the future, we must constantly improve the management system and operation mode of sports associations from the school level, association level and student level, and foster a good association culture, so that to establish the organization and operation mode in all directions. I believe that with the national attention to school sports, sports associations of university students will continue to develop, and become the beautiful campus landscape.

\section{Acknowledgement}

(1) Project source: Supported by the social science foundation of Qiqihar Medical College in 2015. Project name: Research on analysis and service provision on the development of sports associations of university students in Qiqihar Medical College. Project number: QYSKL2015-03.

(2) Project source: Supported by the humanities and social science research project of Heilongjiang Provincial Education Department in 2016. Project name: Research on analysis and service provision on sports participation of urban residents in Heilongjiang. Subject number: No.2016-KYYWF-0898.

\section{References}

[1] Zhong yawei. Realistic Dilemma and Its Countermeasures on the development of University Students Sports Association in Guangdong[J]. Journal of Guangzhou University of Education, 2017, (04): 109-112.

[2] Cong Chen, Cui Zhenyu, Bi Sen, Li Xinyu. An Analysis of the Development of Japanese College Students' Sports Associations[J]. Sports Culture Herald, 2016, (02): 166-170.

[3] Shao Zhengxi, Peng Guoqiang. Dilemma and Its Strategy on the development of University Students Sports Association[J]. Journal of Changzhou Institute of Technology, 2014, (06): 89-92.

[4] Li Weihua. Status and Its Countermeasures on the development of University Students Sports Association in Henan[J]. Neijiang Science and Technology, 2011, (01): 75+100.

[5] Gao Jierong, Chen Linhua. Status and Thinking on the development of University Students Sports Association in Shanghai[J]. Anhui Sports Science and Technology, 2010, (02): 80-83.

[6] Chen Yajin. Status and Its Countermeasures on the development of University Students Sports Association[J]. Hubei Sports Science and Technology, 2010, (02): 129-130.

[7] Hou Zhan Ying. Exploration and Thinking on the Development Direction of College Students' Sports Associations[J]. Journal of Engineering College in Pingding Mountain, 2007, (02): 83-84+86. 